\title{
Choosing Our Futures
}

\section{Carla J. Stoffle, Robert Renaud, and Jerilyn R. Veldof}

\begin{abstract}
Nearly all academic librarians agree that academic libraries have to change in order to respond successfully to the new realities of the higher education environment, rapidly developing information and telecommunications technologies, and the crisis in scholarly communications. But there is little agreement on what must change, how the changes will take place, how fast the changes must occur, and how much change is necessary.
\end{abstract}

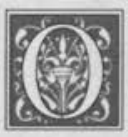

ne view of the future proposes that little or no organizational changes are required. Proponents believe that current structures are adequate to implement the new services, information products, and work functions and tasks that will evolve. Change, where necessary, will occur incrementally. New services and products will be add-ons rather than replacements for what is currently done. The existing fiscal austerity will abate or libraries will somehow manage to live with diminished funds. This view posits that for the foreseeable future, the library will essentially be dealing with traditional formats side by side with new technology. The library will maintain its traditional activities in supporting teaching and research, changing only the tools used.

The countervailing view of the future that the authors hold is that academic libraries must change-fundamentally and irreversibly - what they do and how they do it, and that these changes need to come quickly. Change is going to occur continuously and the pace of change is likely to increase rather than decrease indefinitely into the future. To be successful under these conditions, libraries must reshape the prevailing corporate culture. These actions include giving up the focus on acquiring, processing, and storing physical objects, overcoming the aversion to risk-taking that assumes it is better to miss an opportunity than make a mistake, and conquering the tendency to work in isolation on library, rather than institutional, goals. Libraries must, instead, build into their organizational structures and their approaches to work, the ability to identify, anticipate, and quickly respond to constantly changing customer needs. They must be capable of leaps forward and breakthrough performance. They must reduce cycle times for implementing new services. They must be able to anticipate those needs rather than wait for customer needs to be articulated fully. And they must be ready to abandon formerly successful approaches to work, strategies, processing systems, services, and products that do not continually prove their value to customers. What is

Carla J. Stoffle is Dean of Libraries, The University of Arizona-Tucson; e-mail: cstoffle@bird. library.arizona.edu. Robert Renaud is Team Leader, Bibliographic Access, The University of Arizona; email: renaud@library.arizona.edu. Jerilyn R. Veldof is Social Sciences and Undergraduate Services Librarian, The University of Arizona; e-mail: jveldof@bird.library.arizona.edu. 
required is a transformation, not a refining of organizational structure, work, and external and internal relationships, including those between and among all levels of library staff. A basic rethinking of the mission, values, and assumptions under which library personnel work and plan is necessary.

Although many in the profession ascribe to a view that is somewhere between these two extremes, this essay was commissioned to explore the position that academic libraries must undergo transformational change or risk being left as "storehouses" with skeletal staff and little importance to the institution and its programs. It is not the purpose of this article to describe or prescribe what specific programs, products, or services will characterize libraries that successfully make the transformation. This is not an essay about the digital library or the technologies that will shape and be used by the library. Instead, what the authors are prepared to do in this article is to:

- describe why they believe academic libraries have to undergo radical, revolutionary organizational change, rather than continue to evolve based on past practice;

- identify what some of the organizational elements, assumptions, and approaches are that academic libraries have to change to forge a major institutional role;

- suggest how academic librarians might go about making the necessary changes.

Before tackling the task at hand, a few additional comments to establish the context for the essay may be helpful. First, the authors believe that librarians perform a unique and essential role in academe, given their skills, experience, and philosophical framework. There can be a very bright future for libraries and librarians. However, the authors believe that the success of academic libraries in achieving this future depends on the ability of all library personnel to choose and act quickly. The future, though unpredictable, is within our ability to influence and manage. Thus, the authors have selected the 1997 ACRL National Conference title, "Choosing Our Futures," as the theme of this essay. The authors hope that this theme conveys their basic optimism about the profession. At the same time, they hope to stimulate debate and action among their colleagues that will add to a dynamic national conference program and the development of exciting alternatives that will characterize our various futures.

The authors' second comment is that the view expressed herein is obviously based on their experience at the University of Arizona Library, where transformational change is in its third year. The authors have learned a great deal about such change and how hard it is to achieve and sustain. They do not view these changes with rose-colored glasses, yet their commitment is even more firm about the necessity to transform the library. However, although this essay is informed by their experience, it is not an attempt to sell the University of Arizona answer to the problem and the authors will not specifically address what the University of Arizona has done. What the authors believe is that there will be many solutions and many paths to take. What is important is that we each take responsibility for choosing our future-and act. In other words, just do it!

\section{Why Do We Have to Act Fast and Change Radically?}

Academic libraries are currently affected by the pressures and difficulties faced by society in general and higher education in particular. These combine to create a highly dynamic environment where customer expectations and demographics (ethnicity, gender, and age) are changing as well, forcing corresponding institutional changes. ${ }^{1}$ Customers are increasingly demanding. They are more vocal and critical and want what they want 
now, not tomorrow. At the same time, they have a growing number of viable options to meet their demands if we do not respond. The following summary of these factors provides an overview of the environment both in higher education and within academic libraries.

The literature of higher education is replete with descriptions of the current conditions with their inherent opportunities and challenges and with their dire predictions for the future. ${ }^{2}$ At a time when American society should look to higher education to help create a bright future for its citizens in the global, knowledgebased society of the twenty-first century, the economic and political climate for higher education, especially public education, is more negative than it has ever been. Funding stagnation and cuts are not simply the results of temporary downshifts in the economy, but represent a shift in priorities and a public disillusionment bordering on hostility for what is seen as unnecessary and self-serving academic privilege. The return on investment from both tuition and state appropriations is seen as insufficient, and current costs are being severely questioned. The quality of undergraduate education is being challenged. It is no longer accepted that inputs (student test scores, faculty numbers, expenditures, etc.) denote or measure quality and results.

Additional evidence of the erosion of public confidence is the willingness of state governments and boards to interfere in or micromanage academic policy, procedures, and allocations. Ever more costly studies, planning documents, and reports that describe specific outcomes or results are being demanded. Regulation is increasing. A recent survey of state legislators indicated that they generally no longer trust what they hear from academic administrators and faculty about what higher education is doing or about funding needs. ${ }^{3}$

At the same time, students and alumni, who are the natural allies of the institu- tion, are complaining about academic requirements, scheduling and support difficulties, and the quality of their classroom experiences. Today's students are more diverse in terms of ethnicity and age than at any time in the past, and women now compose more than 50 percent of the undergraduate population. ${ }^{4}$ Little or no accommodation has been made to adjust to student learning styles or to these changing student demographics. The lack of attention to the needs of students not only is undermining current funding, but also is setting the stage for serious con-

\section{At a time when American society should look to higher education to help create a bright future for its citizens, .... the economic and political climate for higher education .... is more negative than it has ever been.}

sideration of states providing students with vouchers for tuition support, rather than state dollars going directly to institutions. $^{5}$

Corporate America also is complaining about the quality of college graduates. Its members are calling for fundamental changes or, worse, beginning to consider developing their own educational programs. Publishing and communications companies especially are anticipating a new spin-off market for their products which would compete against a weakened, declining educational industry.

Higher education is no longer seen as an answer to society's problems or a part of the solution to creating a better future. Instead, higher education is seen as part of the problem. As corporate America is downsizing, utilizing technology to increase productivity, and rethinking all processes and systems, higher education is seen as grasping to maintain the status quo. Members of the academic community are seen as standing above the fray; insisting that only their own members can 
identify or certify quality and how that is achieved. Technology, where applied at all, is an add-on that increases rather than decreases costs. Faculty, graduate programs, and research are valued as ends in and of themselves without regard for their outcomes and society's needs.

There is a great deal of denial among faculty about the need for change. They believe that the solution is for administrators to secure additional funding. Many faculty feel that the current undergraduate curriculum and the delivery systems for that curriculum are adequate. If undergraduate education needs any kind of improvement, these faculty think in terms of the time-honored solutions of increasing the size of the faculty and recruiting better-prepared students, and not in terms of adjusting teaching loads, curriculum, or how the curriculum is delivered. This response has only further angered public officials.

At the same time that public confidence has eroded and funding is stagnant or declining, most institutions are facing increasing costs and the need to invest in infrastructure. Legacy computing systems for student information, personnel work, and financial accounting must be replaced at a huge cost. Buildings must be wired and computing capacity increased to deal with heavy online traffic and a full text and a multimedia environment. Faculty must have appropriate equipment at their desks. Physical facilities must be upgraded after decades of neglect. In addition, costs for products and services for institutions of higher education are rising faster than the rate of general inflation. ${ }^{6}$ This is especially true for academic libraries and the cost of information.

Other major factors affecting higher education are changes in telecommunications and information technologies. These have profound implications for teaching and learning, research, and institutional costs and competitiveness. Perhaps the most important implications outside the library are for the instructional program. There is now the opportunity to restructure completely and rethink the curriculum to focus on learning and active student participation in the learning process. Improved outcomes and decreased costs are within the grasp of our institutions if faculty can be prepared to adjust their thinking about how courses are organized, taught, and scheduled, and if faculty can be educated as to how to use the new technologies to improve learning while reducing costs. ${ }^{7}$ Many institutions have started down this path.

The same technology that offers universities such exciting opportunities paradoxically eliminates the barriers for new players to enter into the educational markets and for formerly less competitive educational institutions to expand. Distance education delivered through the emerging telecommunications technologies will be much more viable than the existing programs delivered through television, correspondence, satellite campus programs, and traveling faculty. The competition for students and funding raised by the growing distance-education option will force a reshaping of higher education.

Just as the new information technologies are beginning to affect the educational programs, they also have implications for the scholarly communication process. As the increasing cost of information is forcing institutions and scholars to rethink how the results of scholarly inquiry are processed, validated, and disseminated, the new technologies hold the promise of creating radical, new forms of scholarship.

There is exciting opportunity, but also considerable challenge. An examination of national information policy, copyright issues, campus rewards and recognition mechanisms, and the economics of information are required as the new technologies are explored. Higher education cannot afford to utilize the technologies to do more with more, but must use and 
shape the results so that more is done with less. This is an environment that runs counter to traditional expectations of faculty and the publishing community, and the academic support systems for both.

The result of the foregoing is that institutions of higher education are grappling with the necessity to restructure, reduce costs, improve educational quality, and make strategic investments to ensure a competitive, vital future in the new knowledge-based society. Fundamental changes in the educational program and scholarly communication process and in how money is allocated and used are just around the corner. A transformation is under way. Academic libraries, as part of the environment of higher education, are being affected by all of the aforementioned factors. In addition, they encounter factors unique to themselves, such as the continuing escalation in the cost of journals, rapidly changing information and telecommunications technologies as they relate specifically to libraries, the growing number of competitors in the information provision business, and the changing needs and demands of their customers.

For more than a decade, information price increases, especially for scientific and technical literature, have exceeded general inflation by large amounts. ${ }^{8} \mathrm{Li}$ brarians and publishers disagree over the reasons for this; however, whatever the reasons, it is clear that the pattern will continue. Even technological advances will not decrease prices or even decrease the rate of price increases. In fact, licensing rather than sales approaches to journal pricing are likely to see charges increase at a greater rate at a time when institutions are increasingly unable, and in some cases even unwilling, to continue to provide budget allocations just to stay even. Although some nontraditional solutions are being sought to this problem, all require upfront investment including the buy-in of the faculty for fundamental changes in the promotion, tenure, and merit system, as well as in how the faculty do their work and who owns faculty copyright. Librarians cannot solve this problem alone. However, the squeeze on libraries makes this a major problem to be resolved, and its resolution will drive changes in how libraries do business.

In the telecommunications arena, the Internet has transformed the potential for access to information and knowledge. New educational and research-oriented software tools to exploit the potential of the Internet and improve access are often designed with little or no input from scholars or librarians, and are flooding the market. Some of the tools are quite

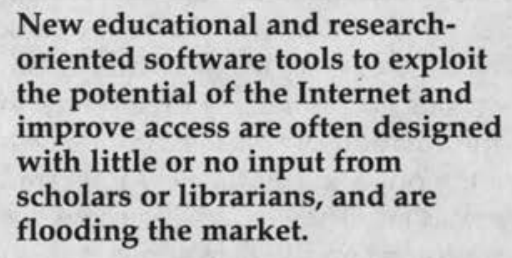

powerful and useful, others are not. All require that library employees have the ability to learn their use rapidly, assess their value, keep up with their continual changes, and teach them in order for the library to play a meaningful role in the transformed campus.

Further, the belief that libraries will manage large print collections side by side with digital ones in the future is less and less valid. More and more information is moving to a digital format. For example, by 1998, very little federal government information will be issued in print. ${ }^{9}$ Also, as the formats of current information are changing, major projects are under way to convert existing print materials into digitized form. The Mellon JSTOR experiment is one example of a project that is likely to demonstrate that it is not only more effective for faculty and students to use materials in a digital form, but that it is cheaper to have older materials in this format for libraries..$^{10}$ This is 
not a development that has been anticipated. Most academic libraries are not prepared to deal with the eventuality that existing print collections will shrink and only a small percentage of new material will be in print format in the next decade.

At the same time, libraries are now faced with very aggressive competitors, on campus and off, for the roles they have traditionally thought of as theirs-information education (information literacy), information consultation and services provision (reference), information selection and organization, information archiving, and information delivery. On campus, some units see their traditional businesses declining and the possibility that they may go out of business. For example, bookstores that are in the textbook selling business face a dismal future. But those bookstores that see themselves in the information dissemination business have the opportunity for new roles and new markets. They could even at some point provide middleman services as ac-

\section{Expectations of traditional library service and response times have escalated, fueled by a culture of instant gratification. The library's bureaucratic environment and response to problems ... by citing rules is no longer acceptable.}

cess points to online bibliographic and full-text databases, making available high-quality and low-cost printing on demand. The same could be said of campus printing and publishing units. Teaching or faculty development centers, which have had difficulty gaining credibility among large numbers of faculty, can and are moving into an emphasis on teaching faculty how to use the new information technologies. They are gaining credibility and new audiences by moving into this role and are garnering considerable campus resources to build classrooms and access to technology that is, or should be, available in the library. Media production units are similarly engaged, and university extension programs are marketing classes in Internet use to the campus. Computing center staff are learning that simply being a manager of the network or the campus hardware systems is not enough. They are finding that these activities can be outsourced to companies that can do the work at a lower cost or that their organizations are likely to be reengineered, which will lead to fewer jobs on the technical side. Computing center staff are looking for new "valueadded" roles that involve service and direct customer contact to solidify their positions. More and more, these involve teaching how to use the new technologies, providing consulting services on how to change teaching and learning, and licensing data for campus use.

Outside competition is just as serious. Many publishers would relish eliminating the library's middleman role if they could find a way to market to the campus community directly. They would be rid of those pesky librarians who question prices and are pushing for changes in the process. Certainly they realize that if libraries go into the online publishing business, it could mean a substantial decline in revenues and would require a rethinking of pricing, marketing, and product development. Technology may indeed one day soon make all of this possible. Library vendors and jobbers, too, are looking for new markets and are threatened by the potential that libraries might go into the publishing business. They are now looking for ways to reach end users directly. Even some of the libraries' own bibliographic utilities and service vendors are exploring ways to market directly to the members of academic communities. Research is going on about how to make it possible to reach libraries' end markets in the guise of improving and expanding services to libraries. Educational materials and tools to teach customers directly how to access in- 
formation, such as OCLC's FirstSearch and special workshops, are now under development. ${ }^{11}$ These companies and utilities see their future viability as not necessarily resting on the viability of libraries - or at least that they cannot completely depend on the viability of libraries. Scholarly societies are caught in the same dilemma. They depend on their publications to fund many of the activities of the society. They need increasing revenue from publications, not reductions in sales and prices. They are in the midst of rethinking how they do business, as well as with whom they do business.

As the library's world is undergoing dramatic shifts, its patrons, those who in the past had to use its services, have become customers-individuals who are able to choose between competing products and services and who may be able to take their library dollars with them. Libraries no longer have a captive audience that must accept and accommodate to the services and standards of quality as established by the library employees. These customers are more discriminating and more demanding. They have increasing options and alternatives such as online information systems marketed directly to the public (e.g., America Online, Compuserve). Despite the fact that libraries have over time conditioned their customers to expect little, faculty and students are less willing to accept slow or shoddy service or to accept personal responsibility for failure in getting what they need. Expectations of traditional library service and response times have escalated, fueled by a culture of instant gratification. The library's bureaucratic environment and response to problems or patron difficulties by citing rules is no longer acceptable. Frontline staff are expected to be problem solvers, not to shift the problems from one unit to another or from one administrative level to another. The current physical organization of libraries (especially reference areas) for the convenience of the librarians and the work the librarians do is under challenge. Also under challenge is the practice of scheduling library work without regard for when users need that work to be done. Library customers expect to be more than served quickly and well. They expect their needs to be anticipated. They expect systems to be easy to use and they expect considerable support in using the new systems.

The factors described above combine to create a dynamic environment unlike any that academic librarians have ever experienced. There is great opportunity for leadership and expanding roles, for being more central and critical to the academic enterprise than libraries have ever really been. At the same time, the price of failure to act now and to begin building the necessary new structures and paradigms will be the decay and degradation of library services and the narrowing of library roles to the point where it will be impossible to make the shift. Librarians will simply be left behind as victims of a changing enterprise. They will be marginalized. Their institutions cannot afford to maintain the status quo and will ask as much of librarians as they do of other members of the campus community. If faculty, curriculum content, teaching methods, course organization, and scholarship have to change, the academic library certainly will-and, undoubtedly, librarians will have to be among the first to change.

\section{What and How Must We Change?}

To succeed - and indeed to thrive - in this new environment, academic libraries must immediately initiate a self-examination. Every assumption, task, activity, relationship, and/or structure has to be challenged. Library émployees must ask themselves, "If we were creating an academic library today, knowing what we know now, how would we organize ourselves and our work to ensure that the library is actively contributing to the achievement of institutional goals?" Then 
they will have to determine what it will take to get there. These will be the critical tasks. Librarians are not about refining or revising existing organizations and work. Libraries must reengineer to achieve breakthrough performance and dramatic improvements. Librarians must live in the future and not in today and with today's problems. They must be willing to invest in the future and choose the future over today if a choice must be made.

Librarians must get away from thinking that libraries are about reference, cataloging, acquisitions, preservation, interlibrary loan, and circulating materialsor even about managing physical facilities and print collections. Simply translating current library activities and tasks into electronic or digitized information will not satisfy the needs of the library's customers, nor will that ensure its future. Libraries must return to their basic business: "to maximize the social utility of graphic records." 12 This may or may not mean that library staff are performing the same, specific tasks over time. Work will undoubtedly change. What will stay the same is the constancy of purpose. Librarians must build new paradigms and frames of analysis, including new language. They must accept that they are educators and knowledge managers first and foremost.

The most fundamental change that has to occur among library employees is a switch from a focus on things and organizing library work around things to a focus on customers and their needs. Libraries must move from defining quality by the size of the inputs-and especially from valuing staff and collection size as "goods" in and of themselves. They must get away from an internal professional evaluation of quality rooted in the context of what librarians agree that libraries do. All services and activities must be viewed through the eyes of the customers, letting customers determine quality by whether their needs have been satisfied. Librarians must be sure that their work, activities, and tasks add value to the customer, and must be prepared to give up less-valued activities and institute new services and programs in very short time cycles. They need to look at customer needs and requests from the perspective of how they can make it happen rather than why they cannot. Increasingly, library staff need to leave the safe and familiar cocoons of their library buildings behind and work directly with customers in classrooms, offices, and laboratories. They must develop connections with their customers instead of thinking of their relationships as one-way. The relationship must be a strong twoway connection with both sides sharing and benefiting. Outreach or even formal liaison assignments are not good enough.

Library organizational structures also must change. Instead of organizing personnel around how librarians do their work, librarians must organize around customers and how they do their work. They must reduce hierarchy, flatten the organization, and eliminate redundancy in order to be more responsive to changing needs and new opportunities and developments. Their organizations must be more flexible, more creative, and more productive. Libraries must do more at higher quality with less. Librarians must give up their need for control and their desire to create stability. ${ }^{13}$ They cannot be afraid to let go of old activities, when justified by cost and quality, through outsourcing and to use the resulting savings to focus on value-added work. They must be prepared, in the words of Tom Peters, to thrive on chaos. ${ }^{14}$ Librarians must trust staff to do the right thing and must make the right decisions for the customers, without supervisors or administrators looking over their shoulders. They must eliminate competition and turf between units and between individuals. They must create a sense of interdependency among staff and give them reasons to work together across unit lines. They must bring goals into sharper focus. And 
they must build a common understanding of, and commitment to, the mission, values, and priorities of educational institutions. No one in the library succeeds if the library does not, and the library does not succeed if the university does not.

Another fundamental change is one from a focus on tasks and the value of complexity to a focus on processes and systems and creating simplicity. Currently libraries fix problems piecemeal, if possible, by throwing money at them. Librarians react to problems in a crisis mode and look only at task-level activities, failing to examine whole processes and systems. They rarely reflect on how changing or fixing one problem or changing one activity affects others in the library. The result is a needless complexity that librarians use to justify their jobs but which results in library staff bloat and poor service. To counter this, library employees must begin studying processes and using process improvement tools. Librarians must begin to collect data and use them as the basis for decision-making rather than rely on subjective impressions and opinions. They must begin to benchmark their costs and processes, not only relative to libraries but also against the competition and other industries that engage in similar activities. They must make decisions based on these costs, and benchmarked data and opportunity costs.

Academic libraries generally work in isolation on campus and in the library world. Librarians behave as if their problems are unique. They act as if they can solve all of their own problems and seek the unlimited funding to do so. They have been singularly unwilling to invest in joint ventures that would benefit their customers or behave in an entrepreneurial way if it meant giving up or reducing their own resources or prestige. Generally, they are arrogant about their roles and do not look for ways to complement their skills, abilities, and dollars with those of other units to create broad ben- efits for the total campus. They really have only superficial relationships with other libraries and, with a few recent exceptions, their resource-sharing activities have never reached their true potential. They have not worked with their vendors on any broad scale to help libraries develop new systems or modify the systems they have already developed. For these reasons, librarians must change their traditional relationships and their view of competition. They need to adopt the flexible attitudes common in the private sector in which, depending on the opportunities at hand, companies become competitors or partners. It is vital that they develop win-win relationships with potential partners on and off campus. This is one of the ways to leverage the resources available to make the future possible.

\section{One of the biggest changes that libraries have to make immedi- ately is a redirection of the budget, including the collection or information budget.}

One of the biggest changes that libraries have to make immediately is a redirection of the budget, including the collection or information budget. Currently, funds generally are first allocated to dayto-day functions and purchases of materials in traditional formats. Then, any extra or new dollars are diverted for strategic priorities, new activities, or investments that will allow the library to do work in new ways. The rationale for this is that the library's customers (faculty and students) will not allow it to reduce services or divert dollars devoted to buying things unless there are actual budget cuts. This belief is rooted in some actual past experiences that, when raised, strike fear in the hearts of university and library administrators. For the most part, librarians have colluded with faculty, and even publishers, in maintaining this belief because it resulted in budget increases and 
served their mutual interest in maintaining the status quo. However, this strategy is no longer going to work. Now libraries must use existing resources to fund strategic priorities first, including those having to do with the collections (access, just-in-time collection building, document-delivery services, and online publishing ventures). Unless such choices are made, no other organizational changes

The roles of the director, assistant directors, and department heads must change from managers, controllers, directors of activities, deciders, and evaluators to leaders, coaches, and facilitators.

are likely to take place and the library will not be able to make the necessary transformation. Libraries must use and redirect what they have now to buy the future. There really is no other choice.

To succeed in making the changes described above, libraries must change how they deal with library personnel. First to go must be unnecessary distinctions and privileges among the different types of library workers. Librarians have unconsciously perpetuated an elitist or classist system modeled after the faculty governance system in their institutions. This system erects barriers to the creativity and productivity of a large part of the library's personnel resource. Instead, libraries need new systems that value all workers for the knowledge and skills they bring to the enterprise, that examine ideas and suggestions based equally on their usefulness regardless of their source, and that involve staff in the decisions that affect their work and makes them feel respected and valued. In addition, the system must provide staff with access to all the information and operational support they need to do their work, regardless of position. Communication is critical.

In the future, all library personnel must perform the duties at the top end of their abilities and rank or classification nearly 100 percent of the time. This is not generally the case now. For example, many librarians are still doing housekeeping activities or performing functions that can be performed by other staff. Holding onto tasks because they have always been done by librarians or because they involve direct work with the customers is no longer sustainable. Librarians should, instead, focus on education, knowledge management, assessment, connection development, information resource development, and aspects of information provision that require the unique education and professional expertise of a librarian. Instead of remaining in the library waiting for customers to ask, librarians need to be out on campus working with customers and making them aware of, and knowledgeable about, information and telecommunication policy issues. Librarians must be highly visible and seek to integrate what they do into the fabric of the institution's instructional and research programs.

Libraries also must move away from a staff performing narrow tasks within tightly defined job descriptions, according to prescribed policies'and procedures, to one empowered to make the daily decisions about what work to do and how to do it in a way that results in delighted customers, the elimination of unnecessary tasks, constantly improving processes, and the fulfillment of library strategic objectives. Staff need to be moved out of the back rooms and onto the front lines as direct-service providers alongside librarians in order to provide new services. Although libraries can no longer guarantee specific staff jobs will exist, they should guarantee that all personnel will have meaningful work.

Expectations of student workers and their performance also must change. Student workers are no longer doing jobs that primarily require their physical presence and little training; rather, they are now performing tasks critical to the main- 
tenance of most academic libraries. Yet many of them are encouraged to view their jobs as a form of financial aid or entitlement. ${ }^{15}$ Viewing students in this manner is costing libraries in customer satisfaction and is a misuse of financial resources. It is also, frankly, a disservice to students.

Perhaps the library personnel who have to make the greatest changes and who will face the most difficulties in the transformation of the library are library administrators. The roles of the director, assistant directors, and department heads must change from managers, controllers, directors of activities, deciders, and evaluators to leaders, coaches, and facilitators. All these administrators must be willing to give up a great deal of decision-making authority and become much more comfortable with being challenged, having to explain, not having the last say, and living with ambiguity and uncertainty. They will no longer be experts and have sole control of information. At the same time, they must exhibit trust in an environment where staff are not likely to reciprocate trust and where staff are still learning the skills necessary for their new functions. Leaders will be held to a higher standard of performance in "walking the talk" or exhibiting new organizational values and behaviors. If administrators do not change, it will be impossible to sustain organizational change.

As leaders, administrators will have to bring the library to a shared vision of the desired future and hold the context in order for staff to make the appropriate decisions to reach that future. Leaders will walk a delicate line between patience and impatience - when to push and when to wait. Leaders will have to be willing to risk errors rather than lose opportunities.

In addition, assistant director and department head positions must undergo changes. Many assistant director positions will evolve from line to staff positions, and department head positions will become term appointments and will have less than 100 percent of their time devoted to administrative functions. This may have a temporary negative impact on the traditional career ladders for librarians, causing disruption for those in these positions now or aspiring to be in these positions in the near future. In the long run, it should lead to even larger pools for administrative jobs as greater numbers of librarians develop leadership, budget, coaching, mentoring, and project management skills, as well as greater skills in working with and understanding other campus constituencies and administrators.

One additional comment about administration is necessary here. The needed library organizational changes on the radical level required will not take place if left in the hands of middle-level management alone. Transformational change will not emanate from the people who have the most at stake in the status quo. Transformational change can come only from senior management support and promotion of groups composed of all ranks, classifications, and levels of faculty and staff making decisions. ${ }^{16}$

To make effective use of human resources, the transformed library must emphasize continuous learning and make the necessary corresponding investment of resources. Personnel must have abundant educational and development opportunities. This will include time away from work in formal settings and must include creative time just to explore new ideas or to learn new software or hardware.

As work changes in response to customer needs and continually improving processes, library personnel must be prepared to take on new tasks or new positions that do not now exist. This preparation must anticipate changes, not come about after changes are made. In addition, all library personnel need to receive leadership decision-making, conflict resolution, and budget and project management 
training because all will be required to assume leadership roles at some point or other.

Personnel policies and traditional personnel systems, including reward and recognition mechanisms, also must be changed in order for libraries to be successful. For example, current classification systems and job descriptions are too narrow and do not give staff the latitude to perform across an increasingly broad range of duties. Compensation systems reward competition and individual goals and achievement, not cooperation and the achievement of library goals. Performance evaluation systems do not result in individual growth and changed behavior, but frequently are morale busters and time wasters. There is very little value added to this activity as currently constructed. ${ }^{17}$

The foregoing are radical changes for existing academic libraries to make. However, even among those who agree that the changes need to be made, these questions may arise: Why now? Why all at once? Isn't this too risky? Shouldn't we wait until we know more about the future? The answer is no to all of the above. "If we wait until the vision is perfectly clear and the risks have vanished, the opportunities will have passed as well."18 Also, the required changes cannot be made piecemeal. Customer-focused, high-quality, constantly changing, con- tinuously learning libraries require a total embrace and implementation of the underlying philosophy and values. Even when this commitment is made and initial reengineering done, staff will need at least three to five years to learn the necessary new skills, adapt the new paradigms, incorporate a new language, develop new working relationships, and internalize the new values and corresponding behaviors. This is all hard work. Results will come slowly. In difficult times it will be easy to return to old behaviors and fall back on old responses. At first, service may decline and staff and customers will question the changes. However, all the problems and difficulties will not be made easier by waiting, nor will the staff's anguish and pain be lessened.

Ultimately, the academic library must change now because its customers need it to change now. They need the new services that the library is best qualified and suited to provide. They need the increased access to knowledge and information that will result from the library's ability to function more effectively as an organization. University campuses need the academic library's leadership and the unique perspectives, values, and skills the library brings to the educational and scholarly process.

The choice is clear. Change now and choose our futures. Change later, or not at all, and have no future.

\section{Notes}

1. Jennifer Jarratt, Joseph F. Coates, John B. Mahaffie, and Andy Hines, "Focusing on the Future," Association Management 47 (Jan. 1995): 16-30; and "To Dance with Change," Policy Perspectives: The Pew Higher Education Roundtable Sponsored by The Pew Charitable Trusts 5, no. 3 (Apr. 1994): $1 \mathrm{~A}-12 \mathrm{~A}$.

2. Lewis J. Perelman, School's Out: The New Technology and the End of Education (New York: William Morrow, 1992); and Eli M. Noam, "Electronics and the Dim Future of the University," Science 270 (Oct. 13, 1995): 247-49.

3. Sandra Ruppert, The Politics of Remedy (Washington, D.C.: National Education Association, 1996).

4. U.S. Department of Commerce, Statistical Abstract of the United States 1995 (Washington, D.C.: U.S. Department of Commerce, 1995), table no. 237, p. 156.

5. Jarratt et al., "To Dance with Change," $4 \mathrm{~A}$.

6. Robert Zemsky and William F. Massy, "Toward an Understanding of Our Current Predica- 
ments: Expanding Perimeters, Melting Cores, and Sticky Functions," Change 27, no. 6 (Nov./ Dec. 1995): 42.

7. Ibid., 46.

8. Michael A. Stoller, Robert Christopherson, and Michael Miranda, "The Economics of Professional Journal Pricing," College \& Research Libraries 57 (Jan. 1996): 9-21.

9. "The Electronic Federal Depository Library Program: Transition Plan, FY 1996-FY 1998," Administrative Notes: Newsletter of the Federal Depository Library Program 16, no. 18 (Dec. 29, 1995): 4-21.

10. William G. Bowen, JSTOR and the Economics of Scholarly Communication (New York: The Andrew W. Mellon Foundation, Oct. 4, 1995). Available at: http://www.mellon.org/jsesc.html.

11. Karen R. Snure, "The FirstSearch Experience at the Ohio State University," Library Hi Tech 9, no. 4 (1991): 25-36.

12. Jesse H. Shera, Libraries and the Organization of Knowledge (Hamden, Conn.: Archon Bks., 1965), 16.

13. Cf., James Champy, Reengineering Management: The Mandate for New Leadership (New York: HarperBusiness, 1995), esp. chapter 6, "What Kind of Culture Do We Want?"

14. Thomas J. Peters, Thriving on Chaos: Handbook for a Management Revolution (New York: Knopf, 1987).

15. Clara M. Lovett, "Small Steps to Achieve Big Changes," Chronicle of Higher Education 42, no. 13 (Nov. 24, 1995): B2.

16. A. E. Guskin, "Reducing Student Costs and Enhancing Student Learning, Part II. Restructuring the Role of Faculty," Change 2, no. 5 (Sept./Oct. 1994): 16-25; and Michael Hammer and Steven Stanton, The Reengineering Revolution: A Handbook (New York: HarperBusiness, 1995), 35-36.

17. Alfie Kohn, Punished by Rewards: The Trouble with Gold Stars, Incentive Plans, A's Praise, and Other Bribes (Boston: Houghton Mifflin, 1993), 183-86.

18. Michael G. Dolence and Donald M. Norris, Transforming Higher Education: A Vision for Learning in the 21st Century (Ann Arbor, Mich.: Society for College and University Planning, 1995), 4.

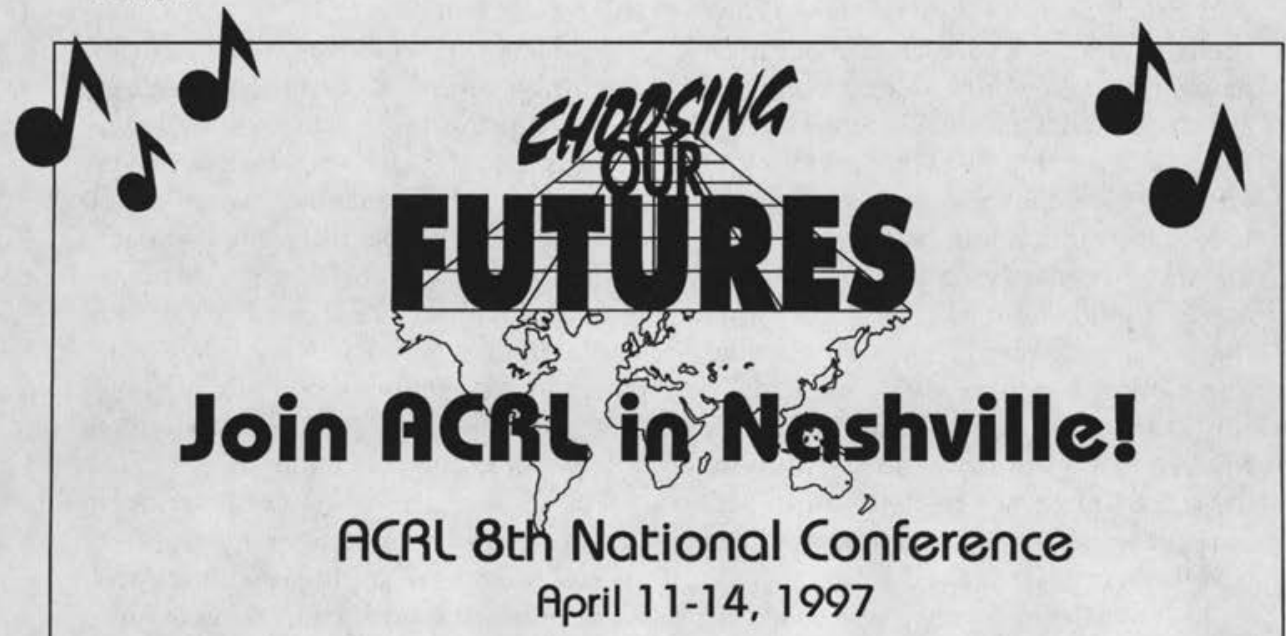

Keep up with the latest on ACRL's conference plans! Point your web browser to: http://www.ala.org/acrl.html 